\title{
RANCANGAN APLIKASI ADMINISTRASI SEWA MOBIL BERBASIS JAVA
}

\author{
Ahmad Sholeh \\ Program Studi Informatika, Fakultas Teknik dan Ilmu Komputer, Universitas Indraprasta PGRI \\ Jalan Raya Tengah No 80, Kelurahan Gedong, Pasar Rebo, Jakarta Timur \\ Jiwaacul@gmail.com
}

\begin{abstract}
Abstrak
Tujuan dari penelitian ini adalah untuk menganalisis sIstem pelayanan pada pelanggan. Metode penelitian yang digunakan untuk menganalisis sistem ini adalah dengan menggunakan metode analisis data dan observasi lapangan. Selain itu peneliti juga menggunakan metode wawancara dan kepustakaan untuk mendapatkan data lebih lengkap. Setelah peneliti merancang dan menganalisa program sistem aplikasi pelayanan rental mobil, maka peneliti dapat menarik kesimpulan bahwa pada aplikasi ini bagian petugas penyewaan dapat menangani pekerjaan, penginputan data-data dengan cepat dan akurat serta dapat diupdate dengan mudah. Semoga dengan adanya aplikasi ini diharapkan akan mempermudah pekerjaan yang memerlukan kecepatan dan ketepatan informasi.
\end{abstract}

Kata Kunci: Java, Sistem aplikasi administrasi, Pelayanan rental mobil

\begin{abstract}
The purpose of this research is to analyze the service sIstem on customers. The research method used to analyze this system is to use data analysis and field observation methods. In addition, researchers also used interview and library methods to obtain more complete data. After the researchers designed and analyzed the car rental service application system program, then the researchers can draw the conclusion that in this application the rental officer can handle the work, input the data quickly and accurately and can be updated easily. Hopefully with this application is expected to facilitate the work that requires speed and accuracy of information.
\end{abstract}

Keyword: Java, System Administration applications, Car Rental service

\section{PENDAHULUAN}

Perkembangan ilmu pengetahuan dan teknologi yang pesat saat ini, terutama dalam dunia komputer dan aplikasi desktop telah banyak membantu kelancaran proses bisnis dalam dunia usaha. Kemajuan ilmu pengetahuan saat ini di tandai dengan banyaknya perkembangan teknologi sehingga banyak dihasilkan alat-alat canggih dan mutakhir. Salah satunya perkembangan teknologi saat ini yang terasa sangat begitu cepat adalah teknologi informasi. Berhungungan perkembangan teknologi yang semakin maju dan modern khususnya pada bidang teknologi dan ilmu informasi membuat beberapa perusahaan mengembangkan bisninsnya agar dapat secara kompetitif dengan perusahaan lain. Maka dari itu dibutuhkan sistem agar dapat membantu proses penyewaan mobil secara efektif dan efisien, terutama dalam bidang komputerisasi.

Dengan perkembangan teknologi aplikasi desktop dan komputer maka munculah apa yang sering disebut reservasi terkomputerisasi. Hal ini dapat mempermudah pelanggan dan juga pegawai untuk melihat informasi produk dan mempermudah perusahaan untuk mendapatkan data secara tepat. Perancangan adalah penggambaran, perencanaan dan pembuatan sketsa atau pengaturan dari beberapa elemen yang terpisah ke dalam satu kesatuan yang utuh dan berfungsi. Menurut (Arif B, 2016) "perancangan menggambarkan rencana umum suatu kegiatan rancangan proyek dan aktivitas-aktivitas khusus yaitu teknik atau metode- metode dalam merancang sesuatu". Belakangan ini jasa sewa mobil sudah cukup banyak, namun sistem yang di gunakan masih secara manual, dalam artian pada suatu pendataan pembukuan masih tersimpan dalam kumpulan berkas yang mungkin saja hal ini dapan menimbulkan kesalahan atau kekurangan yang di lakukan oleh petugas penyewaan, seperti kurangnya informasi mengenai mobil yang akan di sewa dan untuk 
mencari tipe atau merek yang diinginkan dan bisa saja data tersebut hilang sehingga perlu di lakukan pencatatan kembali yang tidak sidikit. Menurut (Subhan, 2012) "sistem dapat diartikan sebagai suatu kumpulan atau himpunan dari unsur komponen atau variabel- variabel yang terorganisasi yang saling berinteraksi, saling bergantungan satu sama lain". Proses pengolahaan data dan pembuatan laporan yang terjadi di hendi rental saat ini masih menggunakan pengolahan data bersifat pencataan dalam bentuk pembukuan. Seluruh bukti pembayaran transaksi setiap hari di kumpulkan dan dilakukan pencataan kedalam buku besar, setiap mobil yang diambil dan di kembalikan dicatat dalam buku mobil dengan tujuan mempermudah perusahaan melakukan pencarian data mobil ketika ada customer yang akan melakukan pemesanan ataupun menanyakan persediaan mobil dan transaksi yang terjadi disetiap hari, cara tersebut ternyata menyulitkan perusahaan dalam proses pencarian data sehingga menyebabkan terjadinya keterlambatan dalam pembuatan laporan karna harus mencari data-data yang telah di arsipkan sebelumnya.

Tujuan dari penelitian ini yaitu merancang sebuah sistem agar dapat membantu pelayanan pada Ren't Car, sebagai sarana untuk pencarian data, membuat administrasi pencatatan dan mempercepat pelayanan pada Ren't Car dengan komputerisasi, merancang aplikasi yang sangat mudah digunakan sehingga pegawai dapat menjalankan aplikasi tanpa mengalami kesulitan dan data yang dimasukan akan mudah diolah menjadi sebuah laporan yang diperlukan. Sedangkan manfaat dari penelitian ini yaitu tersedianya sistem pengolahan data penyewaan mobil yang dapat memberikan kemudahan dalam melakukan penyewaan, mempermudah pegawai dalam pembuatan laporan, merancang aplikasi yang tersusun rapih dan mudah untuk digunakan.

\section{PENELITIAN RELEVAN}

Penelitian oleh (Baaqii, 2017) dengan judul Perancangan Sistem Aplikasi Penyewaan Kendaraan Pada Rental CV.Andri Club Berbasis Java. Tujuan penelitian tersebut adalah merancang Sistem aplikasi penyewaan kendaraan pada rental cv.andri club berbasis java. Dengan adanya sistem ini diharapkan dapat mempermudah pegawai dalam melakukan proses pelayanan, sehingga proses pelayanan dapat terkontrol dan berjalan dengan baik. Penelitian ini sangat berguna dan bermanfaat bagi peneliti, karena dengan adanya penelitian ini dapat menambah wawasan peneliti mengenai system penyewaan kendaraan pada cv.andri club.

Penelitian oleh (Andri Sahata Sitanggang \& Azis Wahab Sutardi S, 2014) dengan judul Sistem Informasi Penyewaan Rental Mobil di CV. Surya Rental Mobil Bandung. Tujuan penelitian ini adalah untuk mengetahui sistem yang berjalan, merancang, serta mengimplementasikan sistem informasi penyewaan rental mobil di cv. Surya rental mobil bandung. Kegunaan penelitian bermaksud agar menambah wawasan dan pengetahuan sekaligus mengimplementasikan teori tersebut kedalam perusahaan. Adapun alat permodelan perancangan sistem dengan menggunakan metode pedekatan model terstruktur dengan menggunakan alat bantu flow map, diagram konteks, DFD, kamus data, normalisasi, dan ERD, software yang digunakan adalah java dengan menggunakan database. Dengan di rancangnya sebuah sistem informasi penyewaan rental mobil ini diharapkan dapat membantu bagian admin atau penyewaan dalam proses penyewaan serta pengembalian mobil dan memudahkan admin dalam pembuatan laporannya.

\section{METODE PENELITIAN}

Metode penelitian dan pengembangan adalah metode penelitian yang digunakan untuk menghasilkan produk tertentu, dan menguji keefektifan produk tersebut. Dalam penelitian ini, peneliti menggunakan metode penelitian Research \& Development.

\section{Metode Pungumpulan Data}

Menurut (Jackson, 2012) "Perancangan Sistem adalah sekumpulan aktivitas yang menggambarkan secara rinci bagaimana sistem akan berjalan. Metode pengumpulan data yang dilakukan oleh peneliti untuk mendapatkan data-data serta informasi untuk mendukung penyempurnaan hasil dari penelitian ini antara lain: 
1. Studi Pustakaan

Studi pustakaan yaitu mengumpulkan data yang diperoleh dari berbagai sumber buku diperpustakaan serta sumber-sumber lain sebagai penunjang dalam menyelesaikan penelitian ini. Studi pustaka dilakukan di Perpustakaan Universitas Indraprasta PGRI, Perpustakaan Nasional, browsing melalui search engine di internet, dan beberapa buku yang terkait dengan penelitian yang dilakukan peneliti.

2. Studi Lapangan

a. Wawancara

Pengumpulan data dengan wawancara ini dilakukan untuk mencari data dan informasi tentang hal-hal yang dibutuhkan dalam penelitian. Wawancara dilakukan dengan lembaga atau instansi yang dijadikan objek penelitian.

b. Observasi

Peneliti melakukan observasi mengenai proses pelayanan di Rent Car, pendataan mobil, penginputan mobil yang di sewa, pembuatan kuitansi untuk pelanggan, pembuatan laporan penyewaan, dan juga pembuatan laporan keuangan. Metode ini diperlukan untuk mengetahui atau mendapatkan data yang tidak mungkin didapat dengan metode wawancara. Metode observasi ini dilakukan dengan cara melakukan pengamatan secara langsung kelapangan mengenai cara sistem kerja yang sedang berjalan saat ini di Rent Car.

\section{HASIL DAN PEMBAHASAN}

DFD Menurut (Jogiyanto, 2016) mendefinisikan bahwa "data flow diagram yang menggunakan notasi-notasi untuk menggambarkan arus dari data sistem, yang penggunaannya sangat membantu untuk memahami sistem secara logika, tersruktur dan jelas".

DFD adalah untuk menggambarkan sistem dari level yang paling tinggi kemudian menguraikannya menjadi level yang lebih rendah. DFD adalah suatu jaringan yang menggambarkan suatu sistem komputerisasi, manualisasi atau gabungan dari keduanya, yang penggambarannya disusun dalam bentuk kumpulan komponen sistem yang saling berhubungan sesuai dengan aturan mainnya.

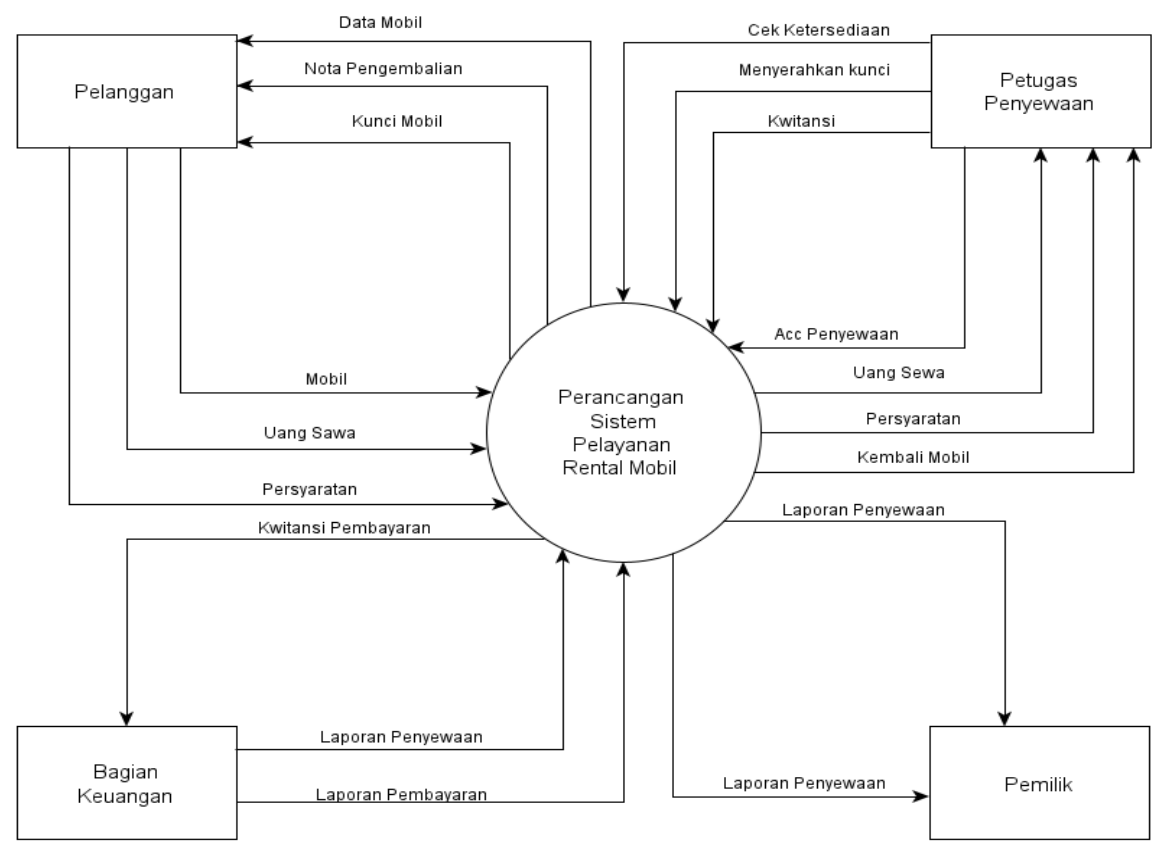

Gambar 1. Diagram Konteks 


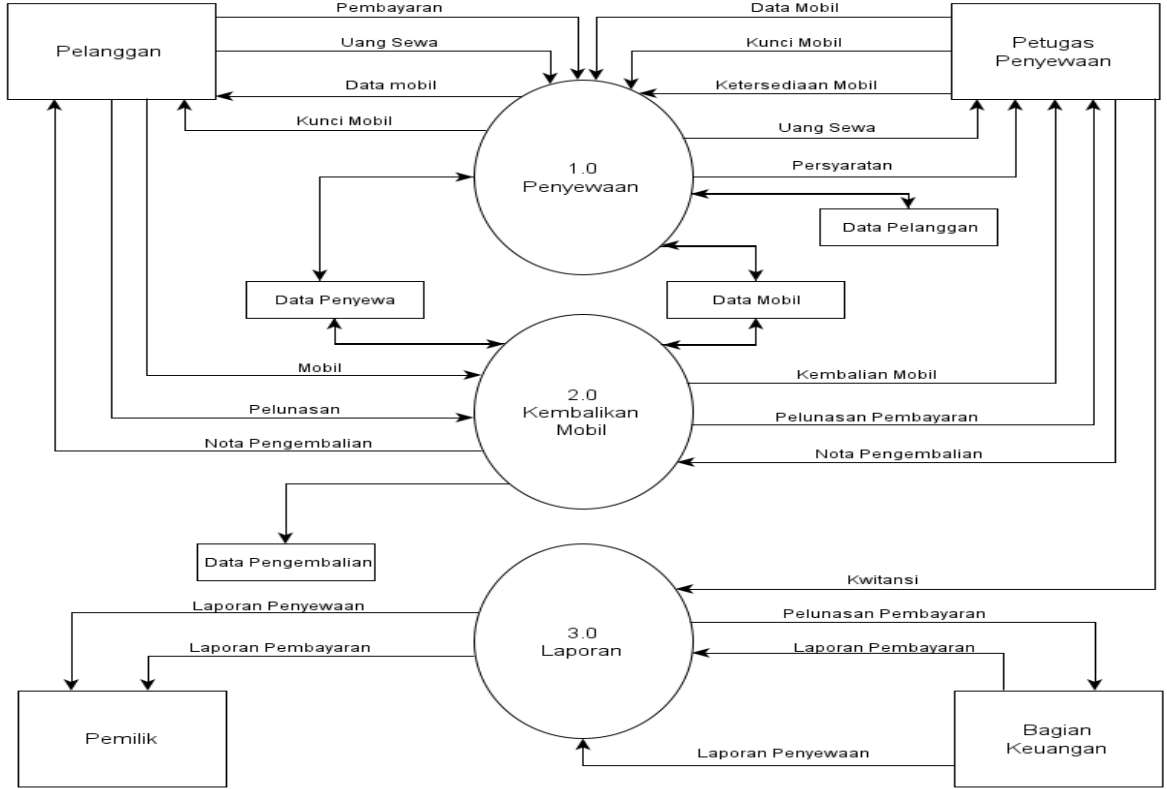

Gambar 2. Diagram Nol

\section{Tampilan Layar}

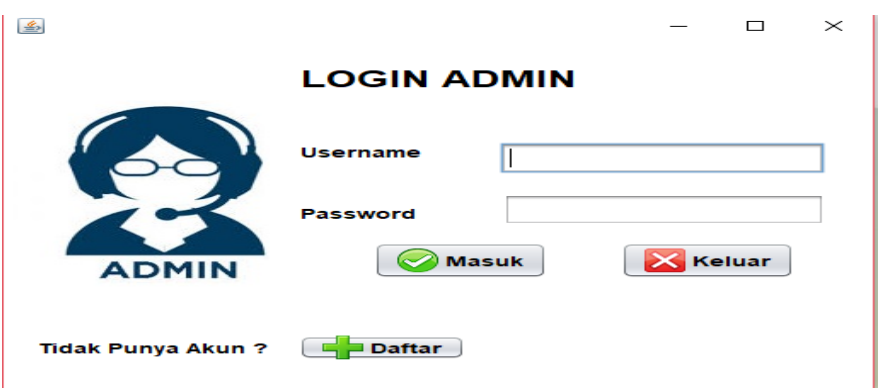

Gambar 3. Tampilan Menu Login

Tampilan ini terdapat pada awal program. Login petugas merupakan salah satu bagian dari sistem yang berfungsi untuk menjaga sistem dari akses pengguna yang tidak di kenal. Sehingga dalam form menu kerahasiaannya tetap terjaga dengan baik.

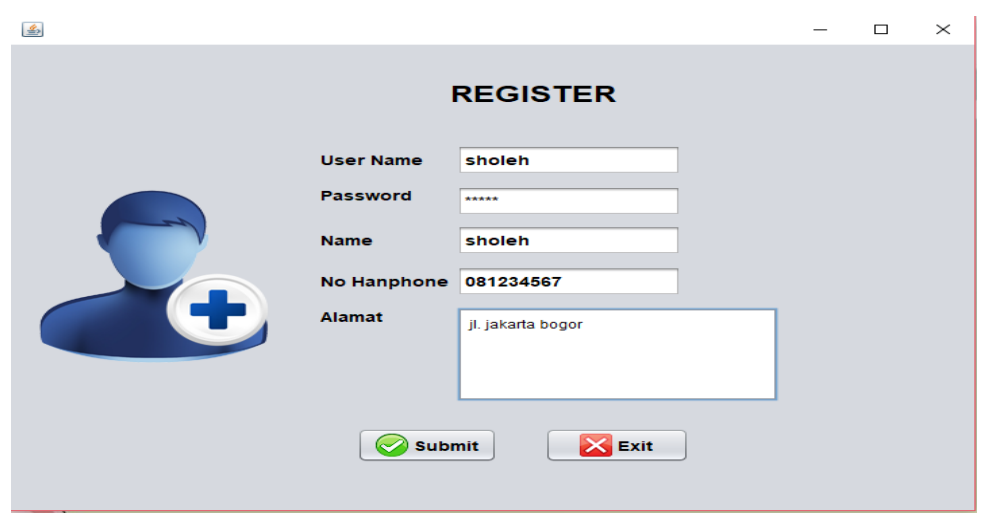

Gambar 4. Menu Register 
Frame daftar petugas merupakan salah satu bagian dari sistem yang berfungsi untuk membuat akun sehingga bisa menjalankan aplikasi ini.

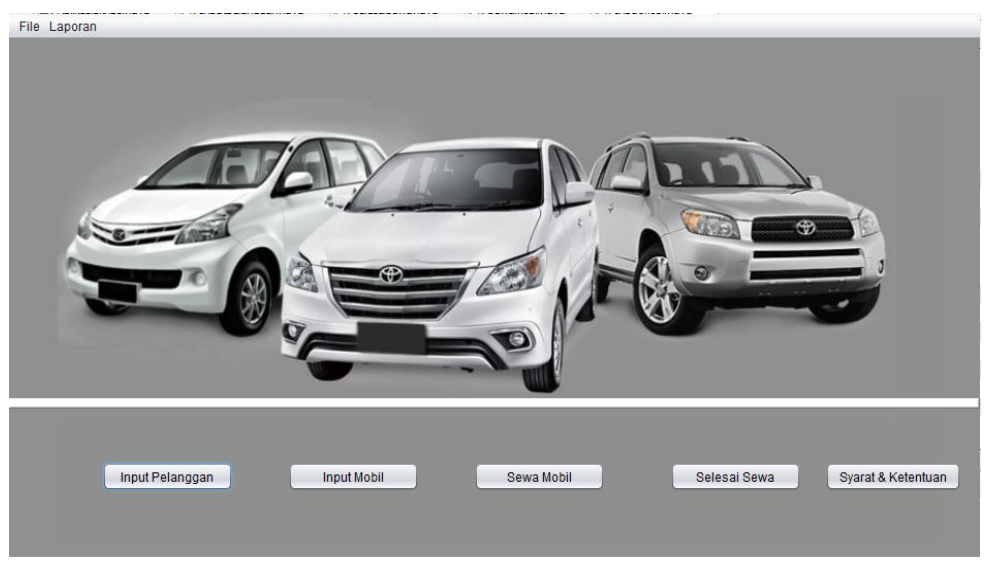

Gambar 5. Tampilan Menu Utama

Pada halaman utama tersedia menubar yang terdiri dari menu master data yang di gunakan untuk memasukan data yang berkaitan dengan sewa mobil, input mobil, input pelanggan, pengembalian mobil.

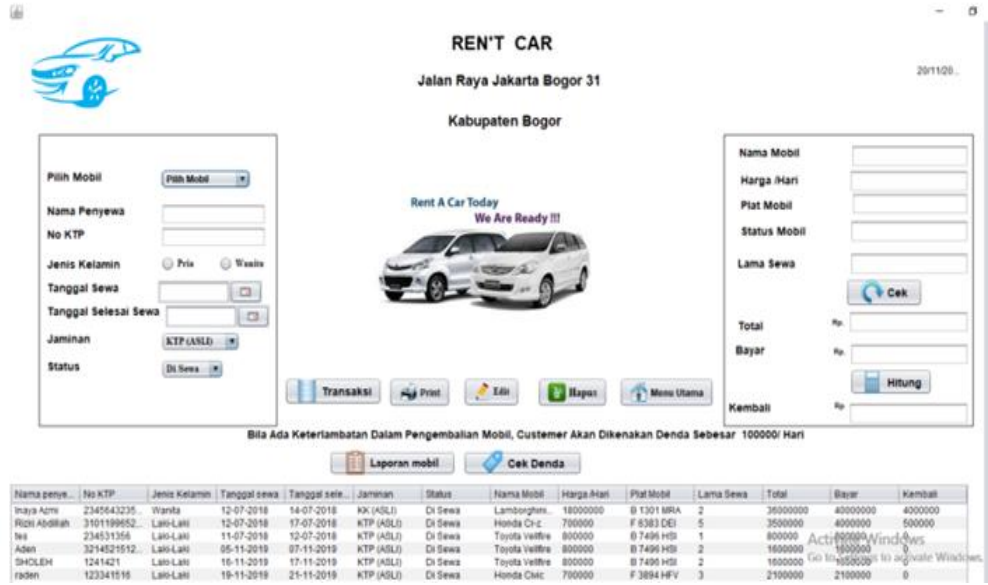

Gambar 6. Tampilan Layar Penyewaan Mobil

Pada menu ini semua transaksi dapat di lakukan antara lain no ktp pelanggan, nama pelanggan nama mobil, harga, mobil. Semua di isi oleh petugas yang nanti di simpan ke dalam database yang nanti akan di laporkan ke pemimpin perusahaan.

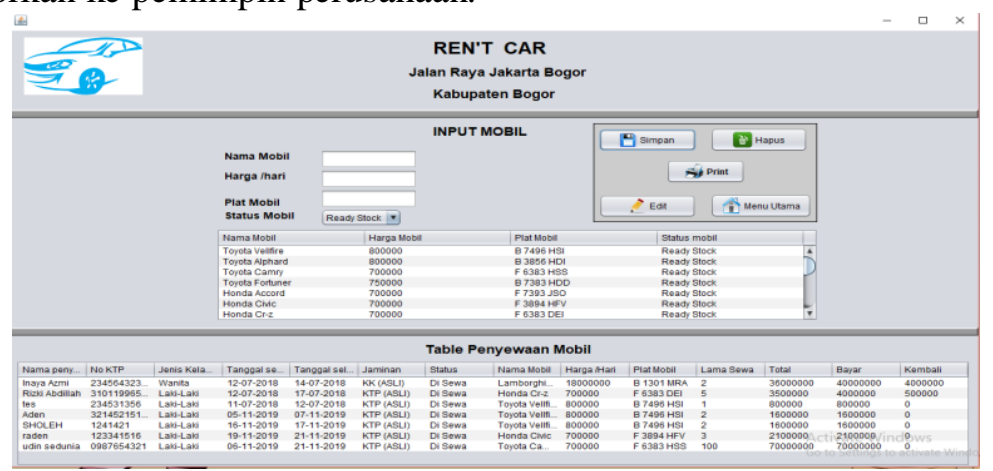

Gambar 7. Tampilan Layar Data Mobil 
Pada halaman input mobil petugas penyewaan bisa memasukan data mobil yang ingin di sewakan, serta memasukan harga mobil. Nanti akan di akses di form sewa mobil yang akan muncul secara otomatis ketika petugas penyewaan mengklik nama mobil.

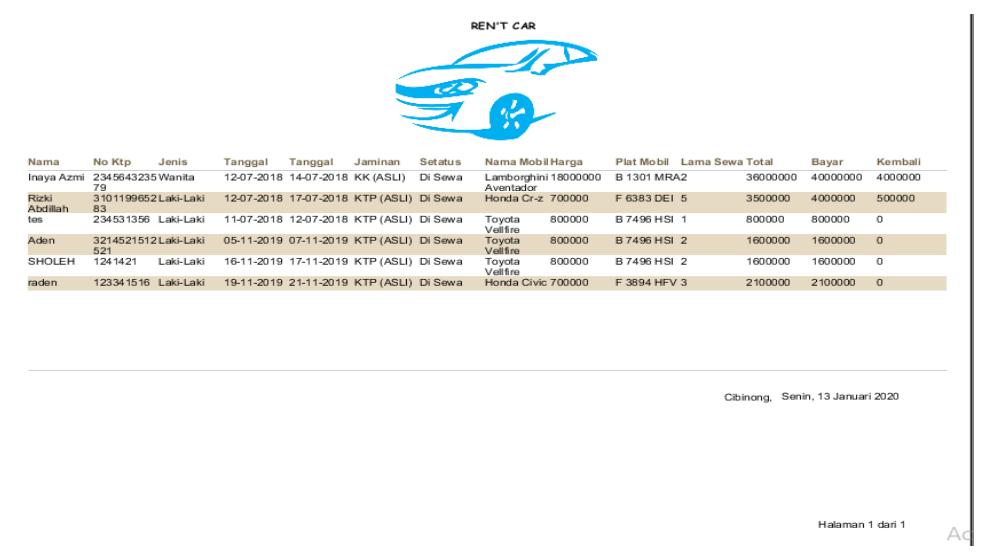

Gambar 8. Tampilan layar Teble Pelanggan

Pada frame table pelanggan semua data pelanggan yang telah mendaftarkan dirinya akan masuk disini dan nantinya akan dibuatkan laporan

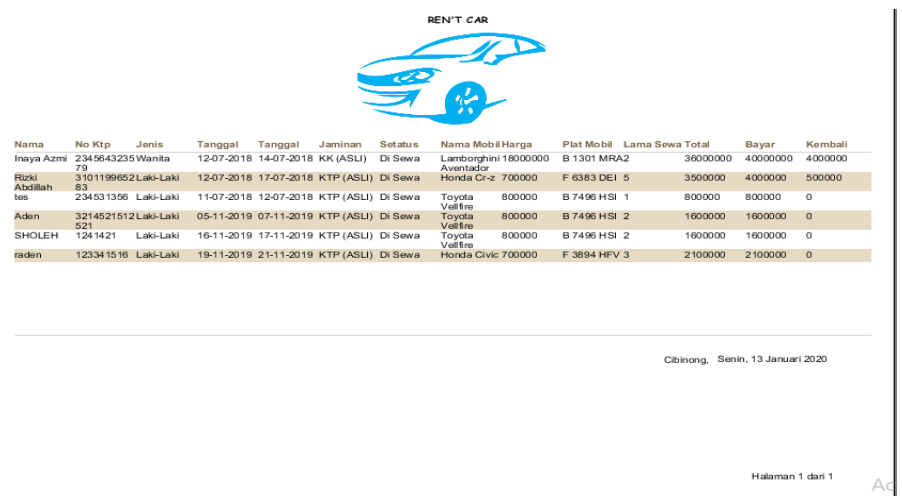

Gambar 9. Tampilan layar Teble Penyewa

Pada frame table penyewaan semua data penyewaan yang telah melakukan transaksi akan masuk disini dan nantinya akan dibuatkan laporan.

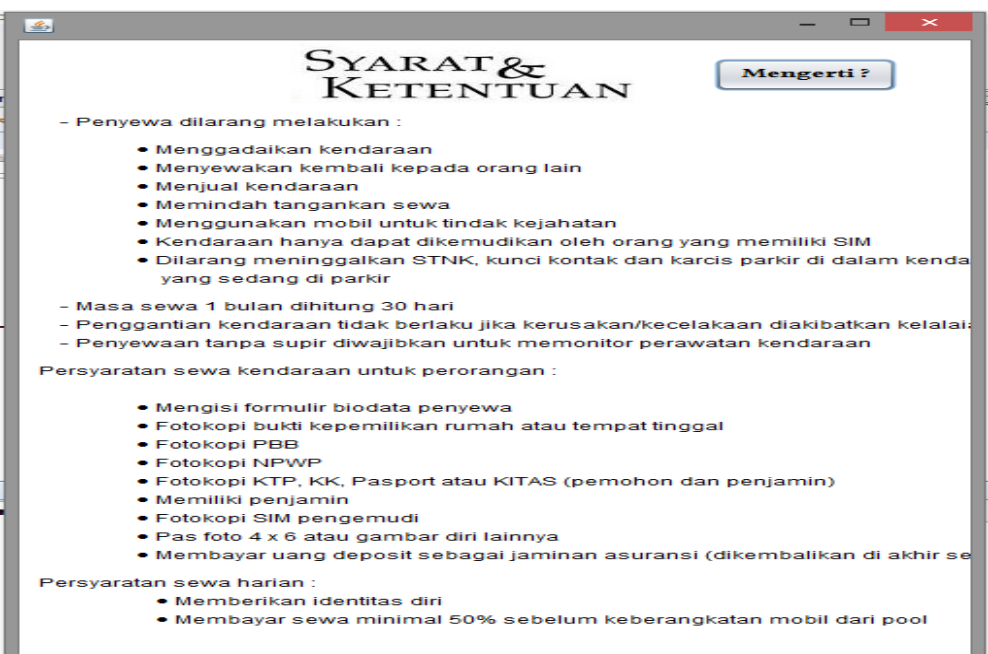

Gambar 10. Tampilan Syarat \& Ketentuan 
Di frame syarat dan ketentuan semua dijelaskan tentang peraturan dalam penyewaan mobil yang nanti akan dibacakan oleh petugas.

\section{SIMPULAN}

Sistem Informasi Pelayanan Ren't Car dibangun dengan menggunakan bahasa pemrograman JAVA dan menggunakan database MYSQL. Dari sistem yang dibuat ini, diharapkan dapat memberikan manfaat antara lain dapat membantu pemilik dan petugas penyewaan dalam mengelola proses pencatatan sewa mobil, transaksi penyewaandan data pelanggan, dapat dipermudah dalam melihat informasi mobil yang akan disewa, status mobil yang tersedia, dan mempermudah pelanggan untuk melakukan transaksi sewa, dapat mempermudah pelanggan dalam proses pemesanan, dan untuk petugas dapat mempermudah dalam proses mengelola pemesanan dan laporan. Sistem ini mempunyai kekurangan yaitu belum mempunyai fasilitas menu promo setiap hari besar maupun liburan ataupun pada hari-hari tertentu.

\section{DAFTAR PUSTAKA}

Andri Sahata Sitanggang, M. K., \& Azis Wahab Sutardi S, K. (2014). Sistem Informasi Penyewaan Rental Mobil di CV. Surya Rental Mobil Bandung. Jurnal Teknologi Dan Informasi UNIKOM, 1(5).

Arif B. (2016). Konsep \& Perancangan. Jakarta: Gramedia.

Baaqii, M. A. (2017). Perancangan Sistem Aplikasi Penyewaan Kendaraan Pada Rental CV.Andri Club Berbasis Java. Universitas Indraprasta PGRI.

Jackson, S. (2012). System analysis and desain in a charging world. Sixth. Jogiyanto. (2016). Analisis dan desain Sistem Informasi. Yogyakarta: Andi.

Pressman, R. S. (2010). Pendekatan Praktisi Rekayasa Perangkat Lunak. Yogyakarta:Andi

Subhan, M. (2012). Analisa perancangan sistem. Yogyakarta Lentera Ilmu Cedikia. 